\title{
SELECTION FOR MATING SUCCESS OF YELLOW MUTANT DROSOPHILA MELANOGASTER: BIOMETRICAL GENETIC ANALYSIS
}

\author{
MAURICE A. DOW* \\ Department of Biology, York University
}

Received 5.vi.76

\begin{abstract}
SUMMARY
A biometrical genetic analysis was conducted on two lines of Drosophila melanogaster that had been selected for wild-type female receptivity and for high mating success of yellow mutant males. Simple additive-dominance models were adequate only for male mating ability measured over l-hour mating periods. The genetic models for female receptivity required the inclusion of sex-linkage, maternal genetic effects and digenic interactions. Some of the genetic parameters were found to change with the duration of testing. The two selection lines had diverged genetically during the selection régime and shared little of the genetic architecture for male mating ability or for female receptivity.
\end{abstract}

\section{InTRODUCTION}

A LARGE amount of work has been done on the behaviour of Drosophila melanogaster and detailed genetic analyses of the bases of the behavioural differences observed between selection lines and between inbred lines have been published. Good examples of the potential information available from such studies are the work of Hirsch (1967) who conducted a series of chromosome assays on strains selected for geotaxis, and Hay (1972) who analysed, with biometrical genetic techniques, the activity and preening of inbred lines raised in different environments.

The benefits of applying the methods of quantitative genetics to behavioural traits have been discussed by Broadhurst and Jinks (1961, 1974), Roberts (1967) and Hay (1972). Briefly, such analyses examine the genetic architecture of a phenotype and lead to inferences about the phenotype's selective history.

The poor mating ability of yellow mutant Drosophila melanogaster males has been known for some time (Sturtevant, 1915; Bastock, 1956). However, artificial selection for increased mating success of yellow males paired with wild-type females has been successful and has resulted in changes in both sexes (Dow, 1976). Therefore, a biometrical genetic analysis of the selection lines has been undertaken to provide information about the genetic architecture of yellow male mating ability and wild-type female sexual receptivity.

\section{MAterials AND METHODS}

Artificial selection for increased success of the mating, wild-type female $\times$ yellow male, was initiated from two inbred stocks of Drosophila melanogaster

* Present address: Department of Zoology, University of Edinburgh, West Mains Road, Edinburgh EH9 3JT, Scotland. 
-a wild-type strain ( $\mathrm{P}_{1} \mathrm{I}$-Oregon- $\left.\mathrm{R}\right)$ and a yellow strain $(y, 1-0 \cdot 0$, Lindsley and Grell, 1968).

All flies were maintained under constant light at $25^{\circ} \mathrm{C}$. Matings during selection were conducted with single pairs, left for 9 days in vials $(20 \times 76 \mathrm{~mm})$ containing $7 \mathrm{ml}$ of propionic acid medium and were scored as successful if progeny were present at the end of this time. Two independent selection lines were produced (I, II). The selection régime is shown in fig. 1. It should be noted that after generation one, the two selection lines were closed and that all matings were between wild-type females (heterozygous at the yellow locus) and yellow males. Furthermore, all successful matings produced four phenotypic classes of offspring, yellow males, wild-type males, yellow females and wild-type females.

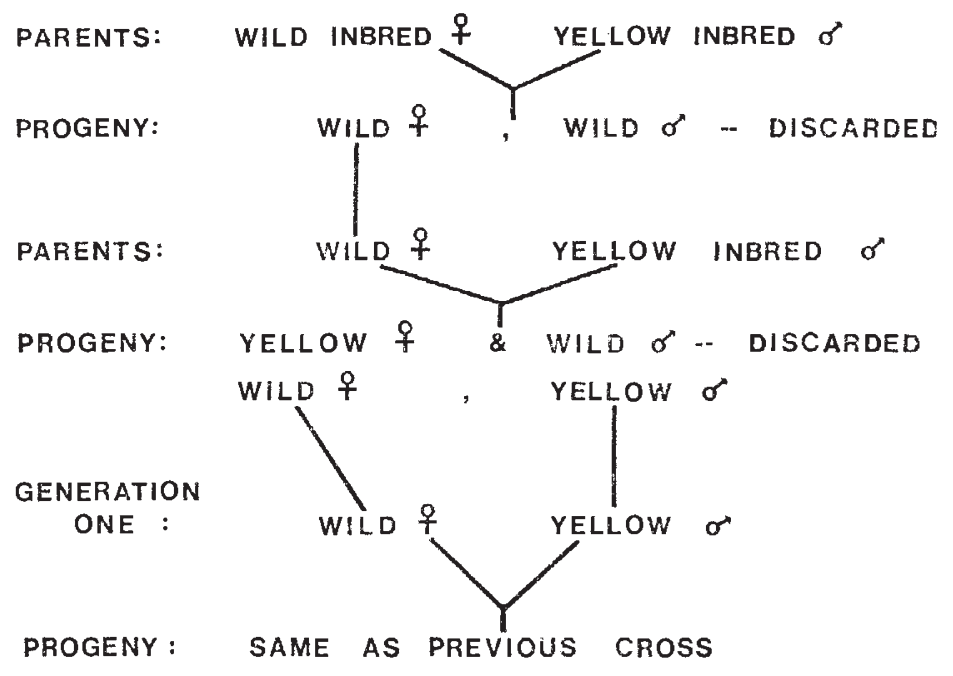

\section{GENERATION}

TWO, ETC.,: SAME AS PREVIOUS GENERATION

FrG. 1. - The selection scheme followed in lines I and II to increase the success of the wildtype female $\times$ yellow male cross.

By the 28th generation of selection, mating success was 100 per cent (adjusted for sterility) in the selection lines, compared with a control mating success of less than 2 per cent. Further details of the selection procedure and results can be found in Dow (1976).

During the course of selection the lines had become inbred, therefore, a biometrical genetic analysis was undertaken without further inbreeding. Each selection line was crossed with both the wild-type (designated as A) and the yellow (designated as $\mathrm{Y}$ ) parental inbred strains in all possible combinations and their reciprocals, to produce $\mathrm{F}_{1}, \mathrm{~F}_{2}$ and $\mathrm{BC}$ generations. Crosses were made with approximately 50 parental pairs in $300 \mathrm{ml}$ bottles. The progeny from different bottles were pooled. All $F_{1}$ generations were grown simultaneously and tested before the segregating generations were grown. The $\mathrm{F}_{2}$ and $\mathrm{BC}$ generations were grown at the same time and were tested on one day. Thus, differences in time of culturing and testing, 
between pooled bottles and between pooled matings are additional sources of variance in the following analyses. However, a series of investigations on the parental inbred lines has indicated that differences in time of culturing and testing, age, bottles, vials, fly density, temperature, and light régime are not significant sources of variance; a heterogeneity chi-square on all such tests yields $\chi^{2}=13 \cdot 68$, d.f. $=13,0.5>P>0 \cdot 3, \mathrm{~N}=3152$.

The mating abilities of the various yellow male genotypes produced by such a set of crosses were measured by pairing each yellow male genotype with selection line II wild-type females and scoring how many females were inseminated. Similarly, the sexual receptivities of the various wild-type female genotypes were measured by pairing each wild-type female genotype with selection line II yellow males and noting how many females were inseminated. By keeping one sex partner constant, the effect of the other sex's genotype on mating success could be evaluated without the complication of differential interaction effects between the sexes. The "tester" flies were pooled across bottles and assigned to generations at random.

These test pairings were conducted by lightly chilling 20 wild-type females and 20 yellow males, and placing them into Perspex observation chambers $(65 \times 45 \times 15 \mathrm{~mm})$. All flies recovered from the chilling within $5 \mathrm{~min}$. The number of matings which occurred in the following hour was noted. The flies were then placed in vials with well yeasted Drosophila medium for a further period to ensure the insemination of all receptive females. This period was 2 days when testing yellow male genotypes for mating ability and 7 days when testing wild-type female genotypes for sexual receptivity. At the end of this time the males were discarded and the females were housed singly to determine if mating had occurred (from the presence of larvae). Since mating ability was assayed by the presence of progeny, it was necessary to exclude the parental inbred lines from the genetic analysis due to their high level of sterility. Therefore, the parental lines were excluded from the analyses for both mating periods.

Flies were 7-12 days old when tested. An attempt was made to test a minimum of three sets of 20 pairs for each generation.

The variability between sets in the percentage of flies mating was examined with the index of dispersion test (Fisher, 1958), which showed that the results did not conform to the binomial distribution; 25 of 105 tests were significant at the 5 per cent level. Therefore, the percentage mating successes for each set of 20 pairs were transformed to angles for analysis (Snedecor and Cochran, 1967). Following the techniques of Mather and Jinks (1971), first degree genetic parameters (see table 1 for the models specifying the parameters) were fitted to the generation means (table 2) by weighted least squares. Each mean was weighted by the inverse of its variance and one iteration of the analysis carried out (Angus, 1974). When only one set was tested, or when the mating success was 0 per cent, the transformed mating success was weighted by the inverse of its theoretical variance $(820 \cdot 8 / 20)$. This occurred seven times.

The parameters included in the genetic models are derived from the following set. The overall mean is specified by $m ;[d]$ and $[h],[d m]$ and $[h m]$, and $[d x]$ and $[h x]$ represent the additive and dominance contributions for the autosomal, maternal and sex-linked genetic effects respectively. Digenic interactions are specified by [i]-homozygote $\times$ homozygote, $[j]$-homozygote $\times$ heterozygote, and $[l]$-heterozygote $\times$ heterozygote. The sex- 
linked additive parameter and the additive maternal parameter have identical coefficients (expectations) in all generations for males. Therefore, the combined effect of these parameters is estimated by the parameter $\left[d^{\prime} x\right]$ in the males; see table 1 .

TABLE 1

Model specifying the coefficients of the genetic parameters fitted to the generation mass

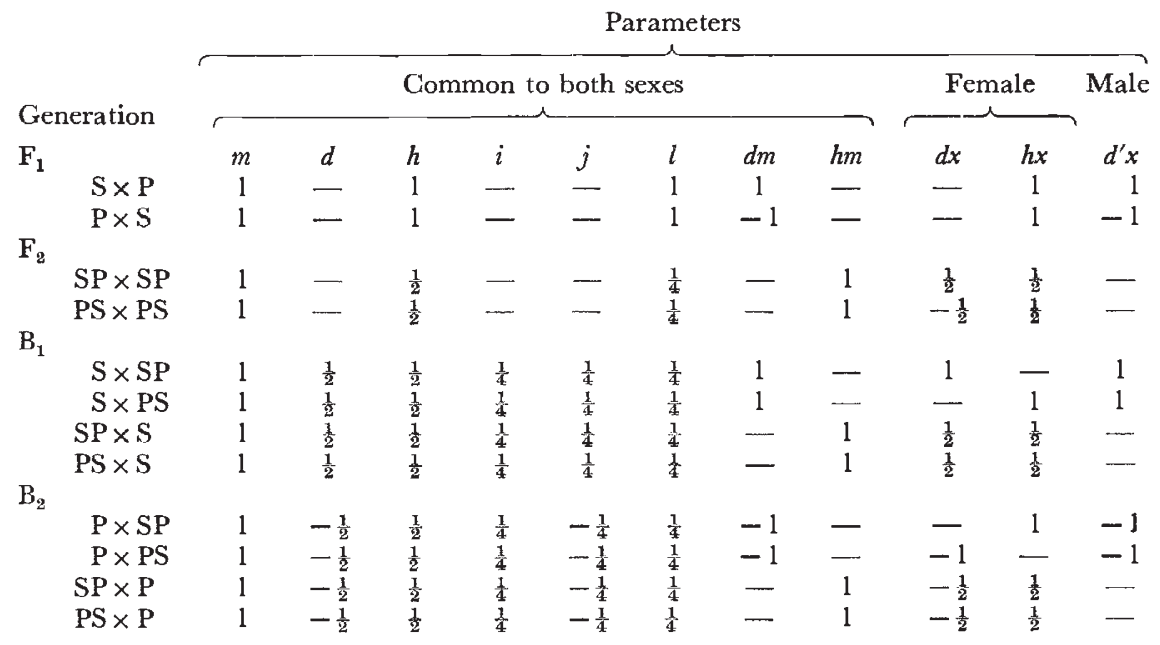

TABLE 2

Mating success of yellow males, and sexual receptivity of wild-type females in the genes ations derived from crosses between the selection lines and the parental inbred lines

\begin{tabular}{|c|c|c|c|c|c|c|c|c|c|c|c|c|}
\hline \multirow[b]{2}{*}{ Generation ${ }^{1}$} & \multicolumn{3}{|c|}{ Yellow I males } & \multicolumn{3}{|c|}{ Yellow II males } & \multicolumn{3}{|c|}{ Wild-type I females } & \multicolumn{3}{|c|}{ Wild-type II females } \\
\hline & $\mathrm{N}^{2}$ & $\begin{array}{l}\text { 1-hour } \\
\text { mean }^{3}\end{array}$ & $\begin{array}{l}\text { 2-day } \\
\text { mean }\end{array}$ & $\mathrm{N}$ & $\begin{array}{l}\text { 1-hour } \\
\text { mean }\end{array}$ & $\begin{array}{l}\text { 2-day } \\
\text { mean }\end{array}$ & $\mathrm{N}$ & $\begin{array}{l}1 \text {-hour } \\
\text { mean }\end{array}$ & $\begin{array}{l}\text { 7-day } \\
\text { mean }\end{array}$ & $\mathrm{N}$ & $\begin{array}{l}\text { 1-hour } \\
\text { mean }\end{array}$ & $\begin{array}{l}\text { 7-day } \\
\text { mean }\end{array}$ \\
\hline & & & & & & & & & & & & \\
\hline $\mathrm{S} \times \mathrm{P}$ & 6 & $12 \cdot 25$ & $54 \cdot 78$ & 3 & 17.98 & $48 \cdot 71$ & 6 & $6 \cdot 30$ & $26 \cdot 67$ & 6 & $13 \cdot 05$ & $48 \cdot 28$ \\
\hline $\mathrm{P} \times \mathrm{S}$ & 3 & $16 \cdot 89$ & 55.55 & 6 & $10 \cdot 80$ & $50 \cdot 60$ & 6 & $6 \cdot 30$ & $29 \cdot 57$ & 6 & $10 \cdot 76$ & $44 \cdot 89$ \\
\hline & & & & & & & & & & & & \\
\hline $\mathrm{SP} \times \mathrm{SP}$ & 6 & $10 \cdot 10$ & $46 \cdot 43$ & 6 & $13 \cdot 71$ & $58 \cdot 04$ & 6 & $13 \cdot 89$ & 33.90 & 5 & $11 \cdot 69$ & $56 \cdot 02$ \\
\hline $\mathrm{PS} \times \mathrm{PS}$ & 3 & $12 \cdot 22$ & $47 \cdot 82$ & 6 & 22.79 & $61 \cdot 41$ & 6 & $16 \cdot 05$ & 48.95 & 7 & $11 \cdot 53$ & $52 \cdot 89$ \\
\hline $\mathbf{B}_{1}$ & & & & & & & & & & & & \\
\hline $\mathrm{S} \times \mathrm{SP}$ & 3 & $9 \cdot 30$ & $39 \cdot 66$ & 1 & $27 \cdot 55$ & $54 \cdot 22$ & 3 & $12 \cdot 29$ & $33 \cdot 69$ & 3 & $21 \cdot 41$ & $61 \cdot 43$ \\
\hline $\mathrm{S} \times \mathrm{PS}$ & 3 & $6 \cdot 30$ & $46 \cdot 83$ & 5 & $18 \cdot 73$ & $57 \cdot 8$ & 6 & 14 . & & 6 & & $46 \cdot 20$ \\
\hline $\mathrm{SP} \times \mathrm{S}$ & 3 & $10 \cdot 90$ & $56 \cdot 48$ & 9 & $20 \cdot 57$ & $55 \cdot 27$ & 6 & $17 \cdot 29$ & $45 \cdot 82$ & 9 & $14 \cdot 87$ & $56 \cdot 49$ \\
\hline $\mathrm{PS} \times \mathrm{S}$ & 3 & $13 \cdot 89$ & $40 \cdot 57$ & 8 & $23 \cdot 32$ & $60 \cdot 65$ & 6 & 21.77 & $50 \cdot 68$ & 6 & $16 \cdot 19$ & $51 \cdot 23$ \\
\hline $\mathrm{B}_{2}$ & & & & & & & & & & & & \\
\hline $\mathrm{P} \times \mathrm{SP}$ & 6 & 11.56 & $41 \cdot 41$ & 6 & $14 \cdot 30$ & $65 \cdot 24$ & 2 & $15 \cdot 29$ & $37 \cdot 88$ & 2 & $10 \cdot 80$ & $36 \cdot 52$ \\
\hline $\mathrm{P} \times \mathrm{PS}$ & 2 & $10 \cdot 80$ & $39 \cdot 02$ & 6 & $15 \cdot 35$ & $64 \cdot 4$ & 9 & $15 \cdot 31$ & & 7 & $10 \cdot 15$ & $40 \cdot 89$ \\
\hline $\mathrm{SP} \times \mathrm{P}$ & 4 & 6.30 & $45 \cdot 75$ & 3 & 13.89 & $48 \cdot 68$ & 5 & $8 \cdot 10$ & 17.90 & 6 & $13 \cdot 20$ & $37 \cdot 47$ \\
\hline$P S \times P$ & 3 & $6 \cdot 30$ & 41.93 & 5 & $13 \cdot 40$ & $53 \cdot 50$ & 6 & $9 \cdot 30$ & 31.54 & 6 & $12 \cdot 40$ & $31 \cdot 27$ \\
\hline
\end{tabular}

${ }^{1}$ For line I males, $\mathrm{S}=\mathrm{Y}, \mathrm{P}=\mathrm{I}$; for line II males, $\mathrm{S}=\mathrm{II}, \mathrm{P}=\mathrm{Y}$; for females, $\mathrm{S}=$ selected line, $\mathrm{P}=\mathrm{A}$.

2 In sets of 20 pairs.

s In degrees. 
The initial models for all crosses included the components $m,[d]$ and $[h]$. The components $\left[d^{\prime} x\right]$ and $[\mathrm{hm}]$ were included in the initial model for yellow line II males since the difference between the reciprocal crosses in $\mathbf{B}_{2}$ ( 2 days) was significant $(\mathrm{d}=27 \cdot 47 \pm 8 \cdot 66, \mathrm{P}<0 \cdot 05)$. Sex-linkage components were included in the initial models for wild-type line II females since the differences between reciprocal crosses in $B_{1}$ were significant ( 1 hour, $\mathrm{d}=6.54 \pm 2 \cdot 67, \mathrm{P}<0.05 ; 7$ days, $\mathrm{d}=15 \cdot 23 \pm 4.47, \mathrm{P}<0 \cdot 05)$. Maternal components were included in the initial models for wild-type line I females since the differences between reciprocal cross in $B_{1}$ and $B_{2}$ were significant ( 1 hour, $\mathrm{B}_{1}, \mathrm{~d}=-12 \cdot 22 \pm 5.56, \mathrm{P}<0.05, \mathrm{~B}_{2}, \mathrm{~d}=13.20 \pm 5 \cdot 76, \mathrm{P}<0.05$; 7 days, $\left.B_{1}, d=-22 \cdot 17 \pm 7.93, P<0.05\right)$.

With the genetic models investigated in this paper, the generation means of the reciprocal backcross families which use $F_{1}$ females should not differ and, therefore, can be used as a test of all sources of error except time of culturing. The data presented in table 2 provide 16 such possible comparisons, all of which are not significant at the 5 per cent level. The 16 probabilities can be combined using the method of Fisher (1958) for a more stringent test. This gives a $\chi^{2}=28.92$, d.f. $=32,0.7>\mathrm{P}>0.5$ and confirms the absence of extraneous sources of variance.

Successive models were generated by a step-down procedure by which non-significant parameters were deleted one at a time in order of increasing $t$ value. The $t$ value was calculated by dividing the estimate of the parameter by its standard error (produced by the analysis). The criteria for acceptance of the final model were non-significance of the overall goodness-of-fit chisquare and significance of all included genetic parameters. If a nonsignificant chi-square could not be obtained, interaction components were included in the initial model and the procedure started again. Since generation replicate means with homogenous variances have not been pooled the goodness-of-fit chi-squares should be treated with caution; the variances used as weights are based on few degrees of freedom. However, computer simulations have shown that the goodness-of-fit chi-square is overestimated by this technique and therefore, the probabilities in tables 3 and 4 are underestimates. Copies of the computer program and the results are available on request.

\section{Results}

\section{(i) Males}

The genetic architecture for the 1-hour mating success of selection line I yellow males was based entirely on a dominant component (table 3 ). In the genetic model for 2-day mating success, $m$ was significant and no change had occurred in the dominance component. Dominance was for higher mating success.

A simple additive-dominance genetic model was adequate for the 1-hour mating success of selection line II yellow males. The dominance component was larger in magnitude than the additive component. Dominance in this line was for lower mating success. In the 2-day model neither the additive nor the dominance component had changed. However, either a sex-linked or maternal component was required in the 2-day model. Dominance in line II was of the same magnitude as that in line I but in the opposite direction. 
TABIE 3

The genetic models for yellow male mating success for mating periods of 1 hour and 2 days for the two selection lines

\begin{tabular}{|c|c|c|c|c|c|c|c|c|}
\hline \multirow[b]{3}{*}{ Parameter } & \multicolumn{4}{|c|}{ Yellow line I males } & \multicolumn{4}{|c|}{ Yellow line II males } \\
\hline & \multicolumn{2}{|c|}{1 hour } & \multicolumn{2}{|c|}{2 days } & \multicolumn{2}{|c|}{1 hour } & \multicolumn{2}{|c|}{2 days } \\
\hline & Value & S.E. & Value & S.E. & Value & S.E. & Value & S.E. \\
\hline$m$ & - & - & $37 \cdot 50$ & $3 \cdot 47$ & $24 \cdot 90$ & 3.20 & $65 \cdot 63$ & $3 \cdot 21$ \\
\hline$[d]$ & - & - & - & - & $7 \cdot 40$ & $2 \cdot 97$ & $6 \cdot 67$ & $2 \cdot 55$ \\
\hline$[h]$ & $16 \cdot 70$ & $I \cdot 19$ & $17 \cdot 72$ & $4 \cdot 53$ & $-13 \cdot 42$ & $4 \cdot 60$ & $-17 \cdot 20$ & $5 \cdot 28$ \\
\hline$\left[d^{\prime} x\right]$ & - & - & - & - & - & - & $-3 \cdot 62$ & $1 \cdot 82$ \\
\hline$\chi^{2}$ & & & 9. & & $6 \cdot I$ & & $13 \cdot($ & \\
\hline d.f. & $\mathbf{P}>$ & & $\mathbf{P}>{ }^{1}$ & & $\begin{array}{r}9 \\
\mathrm{P}>0\end{array}$ & & $\begin{array}{r}8 \\
P>0\end{array}$ & \\
\hline
\end{tabular}

(ii) Females

The genetic model for 1-hour receptivity of selection line I wild-type females contained additive, dominance, and additive maternal components (table 4). The dominance component was larger in magnitude than the additive component and negative; dominance was for lower sexual receptivity. In the model for 7-day receptivity, the dominance and additive maternal components were the same as in the 1-hour receptivity model, but the additive component had increased.

TABLE 4

The genetic models for wild-type female receptivity for mating periods of 1 hour and 7 days, for the two selection lines

\begin{tabular}{|c|c|c|c|c|c|c|c|c|}
\hline \multirow[b]{3}{*}{ Parameter } & \multicolumn{4}{|c|}{ Wild-type line I females } & \multicolumn{4}{|c|}{ Wild-type line II females } \\
\hline & \multicolumn{2}{|c|}{ I hour } & \multicolumn{2}{|c|}{7 days } & \multicolumn{2}{|c|}{1 hour } & \multicolumn{2}{|c|}{7 days } \\
\hline & Value & S.E. & Value & S.E. & Value & S.E. & Value & S.E. \\
\hline $\begin{array}{l}m \\
{[d]}\end{array}$ & $\begin{array}{r}22 \cdot 57 \\
9 \cdot 62\end{array}$ & $\begin{array}{l}2.41 \\
1.91\end{array}$ & $\begin{array}{l}45 \cdot 21 \\
17 \cdot 19\end{array}$ & $\begin{array}{l}4 \cdot 04 \\
3 \cdot 13\end{array}$ & $\begin{array}{r}15 \cdot 81 \\
7.91\end{array}$ & $\begin{array}{l}1.02 \\
1.62\end{array}$ & $\begin{array}{l}57 \cdot 84 \\
16 \cdot 74\end{array}$ & $\begin{array}{l}3 \cdot 08 \\
2 \cdot 24\end{array}$ \\
\hline$[h]$ & -16.27 & 4.01 & $\begin{array}{r}16.08 \\
-16.08\end{array}$ & 6.67 & - & - & - & -2 \\
\hline$[d m]$ & $-3 \cdot 45$ & $1 \cdot 30$ & $-5 \cdot 02$ & $2 \cdot 05$ & $\ldots$ & - & - & - \\
\hline$[h x]$ & - & - & - & - & $-4 \cdot 27$ & 1.92 & $-9 \cdot 81$ & $2 \cdot 64$ \\
\hline [i] & - & - & - & - & - & - & $-32 \cdot 67$ & $10 \cdot 75$ \\
\hline $\begin{array}{l}\chi^{2} \\
\text { d.f. }\end{array}$ & $\begin{array}{r}9.3 \\
P>0\end{array}$ & & $\begin{array}{r}12 \\
8 \\
\mathrm{P}>0\end{array}$ & & $\begin{array}{r}9 \cdot 2 \\
9 \\
P>0\end{array}$ & & $\begin{array}{r}8 . \\
\mathrm{P}>\end{array}$ & \\
\hline
\end{tabular}

The 1-hour receptivity of sclection line II wild-type females was adequately described by $m$, an additive component and a dominant sex-linked component (table 4). In the 7-day model, the additive component had significantly increased and homozygote $\times$ homozygote interaction was present.

The magnitude of $[d]$ was similar in the two sclection lines and in both lines increased to the same extent from the 1-hour to the 7-day mating period. 


\section{Discussion}

Five of the eight genetic models fitted in this investigation have required more than additive and dominance components for non-significant goodnessof-fit $\chi^{2}$. All four of the models for wild-type female sexual receptivity have been in this category. This suggests that the genetic control of female receptivity is more complex than that of male mating ability.

Sex-linked and maternal effects were the most frequently required extra components. This is similar to the results of Hay (1972) who found that the genetic architectures of activity and preening were complex; 15 of 20 models required more than additive and dominance components, and 12 of these required sex-linked and/or maternal effects.

Changes in the values of genetic parameters with the number of tests have been found by Broadhurst and Jinks (1966) and by Wilcock and Fulker (1973). Similarly, changes with the duration of testing have been found in the genetic architectures of yellow male mating ability and wildtype female receptivity in these selection lines. In the males, apart from increases in the means, one of four estimates of genetic parameters was significantly different between the 1-hour and 2-day models. A similar comparison for the females reveals that for them, three of six estimates of genetic parameters were significantly different between the two models.

It has been suggested that selection lines should be replicated to reduce the likelihood that spurious associations are considered significant and to increase the generality of any conclusions (DeFries, Hegmann and Halcomb, 1974). The necessity for considerable replication of selection lines is confirmed by the results presented here. Both selection lines were started from the same parental inbred stocks and the maintenance and selection procedures for them were identical. Yet the lines have diverged over the 28 generations of selection, both behaviourally (Dow, 1976) and genetically. This is not atypical for Drosophila selection experiments (Glayton and Robertson, 1957). Only one genetic parameter has a similar pattern in the two selection lines ([d] for females). However, as the pattern shown by $[d]$ is common to the two selection lines, it may be of interest to speculate about its possible evolutionary significance.

The sexual receptivity of wild-type females to yellow males over a 1-hour mating period shows additive and dominance components in both lines (in line II the dominance component is sex-linked). In both lines the dominance component is for low receptivity to yellow males. This may not be unreasonable, as yellow males have abnormal courtship and have low sexual fitness (Dow, 1976). This suggests an evolutionary history of directional dominance for low sexual receptivity to courting males (yellow) over short mating periods. There were no significant changes in the dominance components for sexual receptivity over a 7-day mating period. But the additive component was significantly increased in the 7-day models of both lines. This suggests a relative increase in sexual receptivity to yellow males and an evolutionary history of selection for an optimum.

This pattern may be adaptive for the following reason. When first confronted with an abnormally courting male, it may be adaptive for a female to show low receptivity; it is likley that she will encounter more males in the near future, some of which may be good courters. However, if a female has encountered only poor courters over a long time period (e.g. 
a week) it may be adaptive for her to be less choosy and to be more receptive to abnormally courting males, otherwise she might not even mate.

The results of selection presented here clearly indicate that the same phenotypic end-point (normal yellow male mating success with wild-type females) can be achieved by many genetic architectures.

Acknowledgments.-I thank the anonymous reviewers and Professor J. L. Jinks for their helpful comments on the manuscript. This research was supported by the National Research Council of Canada.

\section{REFERENCES}

ANGUS, J. 1974. Genetic control of activity, preening and the response to a shadow stimulus in Drosophila melanogaster. Behav. Genet., 4, 317-329.

BAstock, м. 1956. A gene mutation which changes a behavior pattern. Evolution, 10, 42 I-439.

BROADHURST, P. I., AND JINKs, J. L. 1961. Biometrical genetics and behavior: Reanalysis of published data. Psychol. Bull., 58, 337-362.

BROADHURST, P, L., AND JINKs, J. L. 1966. Stability and change in the inheritance of behaviour in rats: a further analysis of statistics from a diallel cross. Proc. Roy. Soc. B, $165,450-472$.

BROADHURST, P. L., AND JINKs, J. L. 1974. What genetical architecture can tell us about the natural selection of behavioural traits. In The Genetics of Behaviour, ed. J. H. F, van Abeelen, pp. 43-63. North-Holland Publ. Co., Amsterdam.

CLAYTON, G. A., AND ROBERTSON, A. 1957. An experimental check on quantitative genetical theory. II. The long term effects of selection. J. Genet., 55, 152-170.

DEFRIES, J. C., HEGMANN, J. P., AND HALCOMB, R. A. 1974. Response to 20 generations of selection for open-field activity in mice. Behav. Biol., 11, 481-495.

Dow, м. А. 1976. Selection for mating success of yellow mutant Drosophila melanogaster: behavioral changes. Behav. Biol., 16, 233-239.

HAY, D. A. 1972. Genetical and maternal determinants of the activity and preening behaviour of Drosophila melanogaster reared in different environments. Heredity, 28, $311-336$.

FISHER, R. A. 1958. Statistical Methods for Research Workers. Oliver and Boyd, Edinburgh. HIRSCH, J. 1967. Behavior-genetic analysis at the chromosome level of organization. In Behavior-Genetic Analysis, ed. J. Hirsch, pp. 258-269. McGraw-Hill, New York.

LindSley, D. L., AND GRell, E. H. 1968. Genetic Variations of Drosophila melanogaster. Carnegie Inst. Publ. No. 627, Washington.

MATHer, K., AND Jinks, J. L. 1971. Biometrical Genetics, 2nd ed. Chapman and Hall, London.

roberts, R. C. 1967. Some evolutionary implications of behavior. Can. F. Genet. Cytol., 9, 419-435.

SNedecor, G. w., ANd cochran, w. G. 1967. Statistical Methods. Iowa State Univ. Press, Ames, Iowa.

sturtevant, A. H, 1915. Experiments on sex recognition and the problem of sexual selection in Drosophila. 7. Anim. Behav., 5, 351-366.

WILCOCK, J., AND FUtKer, D, W. 1973. Avoidance learning in rats: genetic evidence for two distinct behavioural processes in the shuttle box. $\mathcal{H}$. Comp. Physiol. Psychol., 82, 247-253. 